\title{
Habranthus (Amaryllidaceae) da Cadeia do Espinhaço, Minas Gerais e Bahia, Brasil
}

\author{
Habranthus (Amaryllidaceae) in the Espinhaço Range, Minas Gerais and Bahia, Brazil
}

\author{
Renata Souza de Oliveira ${ }^{1,2}$, Julie Henriette Antoinette ${ }^{1}$ \& \\ Paulo Takeo Sano ${ }^{3}$
}

\begin{abstract}
Resumo
Este trabalho apresenta a flora de Habranthus (Amaryllidaceae) da Cadeia do Espinhaço, estados de Minas Gerais e Bahia. Na região, o gênero está representado por sete espécies: H. bahiensis, H. botumirensis, $H$. datensis, H. irwinianus, H. itaobinus, H. lucidus e H. sylvaticus. É apresentada uma chave para separação dos quatro gêneros de Amaryllidaceae que ocorrem na Cadeia do Espinhaço, uma chave e uma tabela diagnóstica para a identificação das espécies de Habranthus, além de descrições, ilustrações e comentários sobre a morfologia e a distribuição geográfica dessas espécies.
\end{abstract}

Palavras-chave: campos rupestres, endemismo, flora.

\begin{abstract}
This study presents the species of Habranthus (Amaryllidaceae) from the Espinhaço Range, states of Minas Gerais and Bahia, Brazil. In this region, the genus is represented by seven species: H. bahiensis, H. botumirimensis, H. datensis, H. irwinianus, H. itaobinus, H. lucidus and H. sylvaticus. A key to the four genera of Amaryllidaceae that occur in the Espinhaço Range, a key and a diagnostic table for the species of Habranthus, plus descriptions, illustrations, comments and geographic distribution of these species are presented.
\end{abstract}

Key words: "campos rupestres", endemism, floristics.

\section{Introdução}

Amaryllidaceae s.s. distribui-se desde as áreas temperadas até as tropicais, com centros de diversidade na África do Sul, América do Sul e Mediterrâneo (Meerow \& Snijman 1998). Possui aproximadamente 850 espécies, 385 delas ocorrem na América do Sul. Está incluída em Asparagales (Monocotiledôneas), formando um clado com Alliaceae e Agapanthaceae (Stevens 2001).

O gênero Habranthus Herb. reúne cerca de 40 espécies, ocorrendo no sul da América do Sul, México e sudoeste dos Estados Unidos (Meerow \& Snijman 1998). No Brasil, ocorrem cerca de 20 espécies, em campos ou cerrados, sendo muitas regional ou localmente endêmicas; a maioria delas foi descrita por Ravenna(1967, 1970, 1974, 1978, 1988, 1999, 2001).

Habranthus é semelhante morfologicamente ao gênero Zephyranthes Herb., e a distinção entre eles é feita principalmente com base na simetria das flores: enquanto Habranthus apresenta flores zigomorfas, Zephyranthes apresenta flores actinomorfas. No entanto, variações e sobreposições entre esses estados podem dificultar uma identificação precisa desses gêneros (Arroyo e Cuttler 1983). Apesar desses gêneros não serem monofiléticos (Meerow et al. 2000), preferiu-se considerar a delimitação tradicional de Habranthus neste tratamento, evitando novas combinações até que estudos filogenéticos ofereçam resolução suficiente para a recircunscrição do grupo.

O presente trabalho tem por objetivo contribuir para o conhecimento de Habranthus e da flora da Cadeia do Espinhaço. São apresentadas chave de identificação para os gêneros de Amaryllidaceae e para as espécies de Habranthus que ocorrem na Cadeia do Espinhaço, além de descrições, ilustrações, comentários e uma tabela diagnóstica para auxiliar no reconhecimento das espécies.

\footnotetext{
Universidade Estadual de Campinas, Instituto de Biologia. R. Monteiro Lobato 970, 13083-970, Campinas, SP, Brasil.

${ }^{2}$ Autora para correspondência: rsolive1@gmail.com

${ }^{3}$ Universidade de São Paulo, Instituto de Biociências. R. do Matão 277, 05508-090. São Paulo, SP, Brasil.
} 


\section{Materiais e Métodos}

Área de estudo

Cadeia do Espinhaço ou Serra Geral é o nome dado a um grupo de serras que se localiza entre os limites 20³5'S e 11 1'11'S (Fig. 1), indo do norte do Quadrilátero Ferrífero, em Minas Gerais, até a Bahia (Gontijo 1993), onde é denominada Chapada Diamantina. Com uma extensão de $1.100 \mathrm{~km}$, larguras entre 50 a 100 km, e altitudes superiores a $1.000 \mathrm{~m}$, constitui o divisor de águas entre a Bacia do Rio São Francisco e o oceano Atlântico(Giulietti \& Pirani 1987). Orelevoé acidentado, com vales profundos e amplos nas formações xistosas e filíticas, e picos de grandes altitudes nas formações quartizíticas e areníticas (Magalhães 1966).

O clima predominante na Cadeia do Espinhaço é o tipo Cwb de Köpen: mesotérmico, com verões brandos e estação chuvosa no verão, temperaturas entre $17,4-19,8^{\circ} \mathrm{C}$, sendo a temperatura média mais

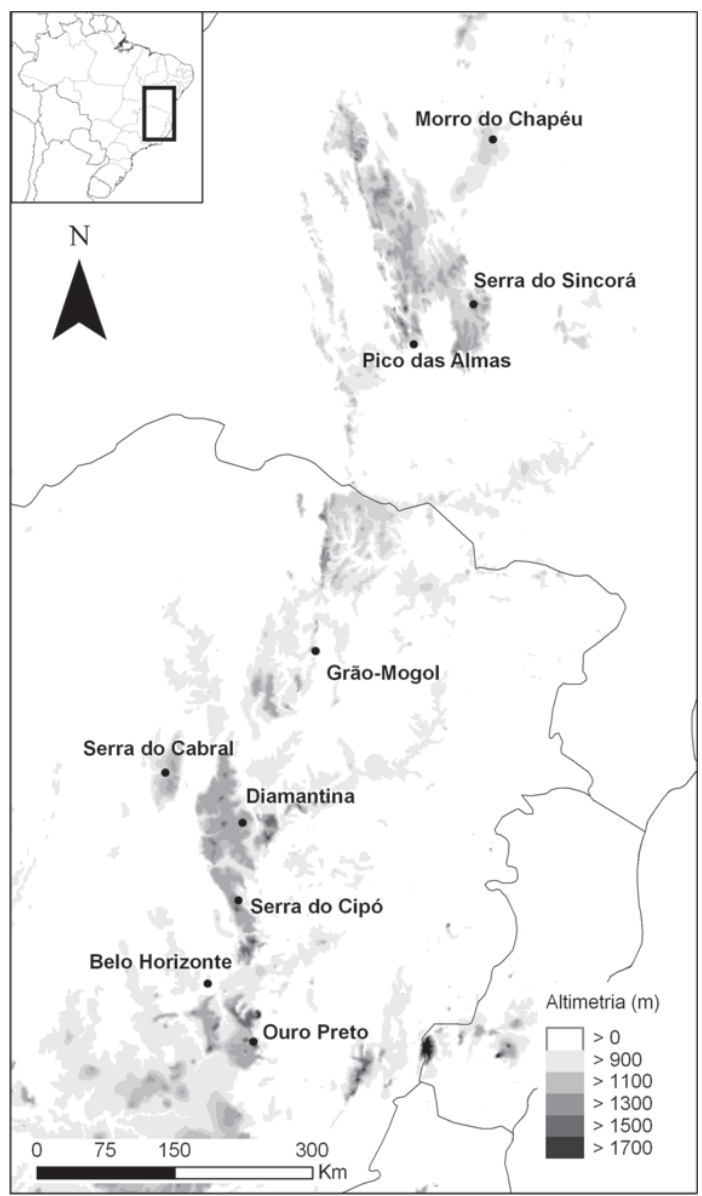

Figura 1 - Mapa da Cadeia do Espinhaço com suas principais localidades.

Figure 1 - Map of the Espinhaço Range with its main locations. quente do mês inferior a $22^{\circ} \mathrm{C}$. A precipitação anual é de aproximadamente $1.500 \mathrm{~mm}$, com um período seco de 3 a 4 meses (inverno) e um período úmido de 7 a 8 meses (Giulietti \& Pirani 1987).

A formação vegetal típica na maior parte da Cadeia do Espinhaço é conhecida como campos rupestres. Segundo Joly (1970), os campos rupestres apresentam o maior índice e a maior diversidade de espécies endêmicas do Brasil. Eles ocorrem acima de $900 \mathrm{~m}$ de altitude e se caracterizam pela presença de plantas crescendo em rochas, solo pedregoso ou arenoso, com substrato rochoso geralmente quartzítico (Magalhães 1966). São entremeados por matas ciliares junto aos cursos d'água, manchas de cerrado, e capões de mata acompanhando as ondulações do terreno (Magalhães 1966).

\section{Procedimentos}

Foi examinado material depositado nos herbários BHCB, CESJ, ESA, GFJP, HB, HUFU, MBM, OUPR, R, RB, SP, SPF, UEC e VIC (abreviaturas segundo Holmgren et al. (1990)) e realizadas observações de algumas populações no campo, bem como a partir de material conservado em álcool 70\%. As descrições morfológicas foram preparadas com auxílio de estereomicroscópio, as medidas obtidas com paquímetro e a terminologia baseada em Radford et al. (1974).

\section{Resultados e Discussão \\ Tratamento taxonômico \\ Amaryllidaceae s.s.}

Ervas com bulbos subterrâneos perenes, terrestres, eventualmente aquáticos ou epifíticos. Folhas sésseis ou subpecioladas, simples, dísticas, concentradas basalmente, lanceoladas a elípticas. Inflorescências em escapos terminais, frequentemente umbeliformes, subtendidas por 2 brácteas livres ou concrescidas somente de um lado ou formando um tubo; bractéolas geralmente presentes, pequenas e filiformes. Flores de uma a muitas, sésseis ou pediceladas, eretas ou declinadas, actinomorfas ou zigomorfas, monoclinas, geralmente protândricas; perigônio com 6 tépalas em 2 verticilos, conatas na base, formando um hipanto curto (quase imperceptível) a longo; corona às vezes presente, formada por projeções das tépalas, às vezes conspícua ou em anel na base dos filetes, ou de fímbrias; estames 6, declinados ou eretos, em 2 verticilos, subiguais ou de comprimentos distintos, filetes inseridos na fauce, anteras dorsifixas, com deiscência longitudinal; estigma capitado, trilobado ou trífido, estilete filiforme, ovário ínfero, trilocular, óvulo 
de placentação axilar. Fruto cápsula, raramente baga. Sementes globosas ou subglobosas, usualmente com fitomelanina negra ou marrom nas células da testa.
$\mathrm{Na}$ Cadeia do Espinhaço, ocorrem quatro gêneros: Griffinia Ker Gawler, Habranthus, Hippeastrum Herb. e Rhodophiala C. Presl.

\section{Chave para identificação dos gêneros de Amaryllidaceae da Cadeia do Espinhaço}

1. Brácteas fundidas na metade inferior, formando um tubo Habranthus

1'. Brácteas livres ou fundidas somente em um lado.

2. Folhas elípticas, pecioladas ou subpecioladas; escapo sólido; flores azuis, brancas ou violeta; estigma capitado; sementes globosas, túrgidas, brancas ou rosadas

2'. Folhas lanceoladas ou lineares; escapo oco; flores rubras, avermelhadas, laranjas ou rosadas; estigma trífido ou trilobado; sementes discóides achatadas, negras.

3. Folhas lanceoladas, mais de $2 \mathrm{~cm}$ larg.

Hippeastrum

3'. Folhas lineares, menos de $1 \mathrm{~cm}$ larg. Rhodophiala

\section{Habranthus Herb.}

Folhas anuais, lineares ou filiformes. Escapo oco, cilíndrico; inflorescência reduzida a uma única flor; brácteas fundidas na metade inferior formando um tubo. Flores declinadas, infundibuliformes ou crateriformes, zigomorfas. Corona de escamas pequenas ou de fímbrias às vezes presente; tépalas elípticas ou ovais. Estames declinado-ascendentes, filetes filiformes, desiguais. Anteras oblongas. Estigma trífido ou trilobado, estilete filiforme. Sementes achatadas.

Cerca de 40 espécies, com distribuição desde o sul da América do Sul até o sudoeste dos Estados Unidos.

Na Cadeia do Espinhaço, estados de Minas Gerais e Bahia, o gênero está representado por sete espécies, ver tabela diagnóstica (Tab. 1).

\section{Chave para as espécies de Habranthus da Cadeia do Espinhaço}

1. Filetes em 2 comprimentos diferentes; paraperigônio caloso, restrito à região oposta ao filete.

2. Flores infundibuliformes; ápice das tépalas externas obtuso, com região papilar concentrada no ápice, obovóide; perigônio com nervuras mais escuras (endêmica de Rio de Contas, BA) .....

6. H. lucidus

2'. Flores crateriformes; ápice das tépalas externas mucronado, com região papilar oboval; perigônio com nervuras não aparentes (ampla distribuição, norte de Minas Gerais, Nordeste e Centro Oeste)

5. H. itaobinus

1'. Filetes em 4 comprimentos diferentes; paraperigônio franjado ou reduzido a apêndices setiformes, pareados e flanqueando os filetes na base da porção livre.

3. Paraperigônio franjado de fímbrias digitiformes.

4. Folhas 4-7 mm larg.; perigônio branco a rosado, com nervuras mais escuras; estigma com lobos 4-11 mm compr. 3. H. datensis

4'. Folhas ca. $3 \mathrm{~mm}$ larg.; perigônio rosado, sem nervuras aparentes; estigma com lobos $1-2 \mathrm{~mm}$ compr.

2. H. botumirimensis

3'. Paraperigônio formado por apêndices setiformes pareados e flanqueando os filetes na base da porção livre.

5. Lobos das brácteas eretos; paraperigônio formado por apêndices setiformes eretos (sul da porção mineira da Cadeia do Espinhaço)

4. H. irwinianus

5'. Lobos das brácteas deflexos; paraperigônio formado por apêndices setiformes curvados (ampla distribuição no Nordeste).

6. Folhas filiformes; flores infundibuliformes; hipanto 3-5 mm compr. (endêmica de Morro do Chapéu, BA) 1. H. bahiensis

6'. Folhas lineares; flores crateriformes; hipanto 10-23 mm compr.; (distribuição no Nordeste) 7. H. sylvaticus 
Tabela 1 - Caracteres morfológicos diagnósticos das espécies de Habranthus ocorrentes na Cadeia do Espinhaço.

Table 1 - Morphological diagnostic characters of Habranthus species that occurs in Espinhaço Range.

\begin{tabular}{|c|c|c|c|c|c|c|c|c|c|}
\hline Espécie & $\begin{array}{l}\text { Lobos } \\
\text { das } \\
\text { brácteas }\end{array}$ & Folha & Flor & $\begin{array}{l}\text { Perigônio } \\
\text { (cor) }\end{array}$ & $\begin{array}{l}\text { Hipanto } \\
\text { compr. } \\
\text { (cm) }\end{array}$ & $\begin{array}{l}\text { Ápice das } \\
\text { tépalas } \\
\text { externas }\end{array}$ & $\begin{array}{l}\text { No compr. } \\
\text { dos } \\
\text { filetes }\end{array}$ & $\begin{array}{l}\text { Lobos do } \\
\text { estigma, } \\
\text { compr. } \\
(\mathrm{cm})\end{array}$ & Paraperigônio \\
\hline Habranthus bahiensis & Deflexos & Filiforme & Infundibuliforme & Púrpura & $0,3-0,5$ & Agudo & 4 & $0,1-0,2$ & $\begin{array}{l}\text { Apêndices } \\
\text { setiformes } \\
\text { curvos }\end{array}$ \\
\hline $\begin{array}{l}\text { Habranthus } \\
\text { botumirimensis }\end{array}$ & Eretos & Linear & Infundibuliforme & Róseo & $0,2-0,3$ & Mucronado & 4 & $0,1-02$ & $\begin{array}{l}\text { Franjado, } \\
\text { com fímbrias } \\
\text { digitiformes }\end{array}$ \\
\hline Habranthus datensis & Eretos & Linear & Infundibuliforme & $\begin{array}{l}\text { Branco a } \\
\text { rosado/ } \\
\text { nerv. }+ \\
\text { escuras }\end{array}$ & $0,1-0,4$ & Obtuso & 4 & $0,4-1,1$ & $\begin{array}{l}\text { Franjado, } \\
\text { com fímbrias } \\
\text { digitiformes }\end{array}$ \\
\hline Habranthus irwinianus & Eretos & Filiforme & Infundibuliforme & Rosa a lilás & $0,1-0,2$ & Agudo & 4 & $0,2-0,3$ & $\begin{array}{l}\text { Apêndices } \\
\text { setiformes } \\
\text { eretos }\end{array}$ \\
\hline Habranthus itaobinus & Eretos & Linear & Crateriforme & $\begin{array}{l}\text { Branco a } \\
\text { rosado }\end{array}$ & $0,2-0,8$ & Mucronado & 2 & $0,1-0,2$ & $\begin{array}{l}\text { Calosidades } \\
\text { opostas aos } \\
\text { filetes }\end{array}$ \\
\hline Habranthus lucidus & Eretos & Linear & Infundibuliforme & $\begin{array}{l}\text { Rosado/nerv. } \\
+ \text { escuras }\end{array}$ & $0,2-0,5$ & Obtuso & 2 & $0,1-0,2$ & $\begin{array}{l}\text { Calosidades } \\
\text { opostas aos } \\
\text { filetes }\end{array}$ \\
\hline Habranthus sylvaticus & Deflexos & Linear & Crateriforme & $\begin{array}{l}\text { Branco ao } \\
\text { púrpura }\end{array}$ & $1,0-2,3$ & Agudo & 4 & $0,2-0,3$ & $\begin{array}{l}\text { Apêndices } \\
\text { setiformes } \\
\text { curvos }\end{array}$ \\
\hline
\end{tabular}


1. Habranthus bahiensis Ravenna, Onira 1(8): 53. 1988.

Fig. 2 a-c

Bulbo marrom, globoso, 1,9-2,9 cm diâm.; colo do bulbo 1,5-4 cm compr. Folhas verdes, filiformes, 5-9-nervadas, até ca. 12,5 ×0,1-0,3 cm durante a floração; ápice agudo. Escapo verde, avermelhado no ápice, $9-17 \times 0,2-0,3 \mathrm{~cm}$. Brácteas verde-claras a acinzentadas, 1,5-3,5 cm compr., com lobos deflexos, 0,8-2,5 cm compr.; bractéolas não observadas. Pedicelo verde-avermelhado, $1,8-4 \mathrm{~cm}$ compr. Flores infundibuliformes, 4,9-6,7 cm compr.; hipanto 3-5 mm compr. Tépalas púrpura, oblanceoladas; as do verticilo externo 11-15-nervadas; ápice agudo, apículo conspícuo, com região papilar em faixa longitudinal; tépala superior 4,5-6,1 $\times 0,8-1,2 \mathrm{~cm}$; tépalas laterais inferiores $4,4-6,4 \times 0,8-1,2 \mathrm{~cm}$. Tépalas do verticilo interno 7-13-nervadas; ápice agudo; tépalas laterais superiores 4,4-6,6 ×0,6$1 \mathrm{~cm}$; tépala inferior $4,3-6,3 \times 0,8-1,2 \mathrm{~cm}$. Filetes avermelhados, em 4 comprimentos diferentes; o oposto à tépala superior 2-4 cm compr.; os opostos às tépalas laterais inferiores $3-4,5 \mathrm{~cm}$ compr.; o oposto à tépala inferior 3,4-4,9 cm compr.; e os opostos às tépalas laterais superiores $3,3-4,8 \mathrm{~cm}$ compr. Anteras amarelas, 2-4 mm compr. Paraperigônio formado por apêndices setiformes recurvados, pareados e flanqueando os filetes na base da porção livre. Estilete avermelhado 3,9-5,2 cm compr. Estigma branco, trilobado, lobos 1-2 mm compr. Ovário marrom-avermelhado, largamente obovóide, 2-4×2-4 mm, 12-18 óvulos por lóculo. Fruto e sementes não observados.

Material examinado: BAHIA: Morro do Chapéu, $11^{\circ} 35^{\prime}$ 'S, $41^{\circ} 13^{\prime}$ W, 28.XI.92, M.M. Arbo et al. 5374 (SPF); ib., 16.I.1977, G. Hatschbach 39682 (MBM); margens do córrego Agreste, Jacobina, BA-426, 11²9'14,2” S, 4101'21,7'W, 8.V.1999, R. Romero et al. 5694 (UEC).

Habranthus bahiensis assemelha-se a $H$. sylvaticus; ambas apresentam flores com tépalas púrpura, brácteas com lobos deflexos e paraperigônio formado por apêndices setiformes recurvados, pareados e flanqueando os filetes na base da porção livre. No entanto, Habranthus bahiensis pode ser diferenciada pelas folhas filiformes, hipanto curto em relação ao tamanho da flor (3-5 mm compr.) e flores infundibuliformes (Tab. 1).

É endêmica de Morro do Chapéu (BA) (Fig. 3). Não há dados sobre habitat, mas foi coletada em beira de córrego, o que sugere preferência por lugares úmidos.
2. Habranthus botumirimensis R.S. Oliveira, Kew Bull. 64(3): 538. 2009.

Fig. 2 d-f

Bulbo marrom, globoso, ca. 2,5 cm diâm.; colo do bulbo 2,5-3 cm compr. Folhas verdes, lineares, 9-12-nervadas, até ca. $3 \times 0,3 \mathrm{~cm}$ durante a floração; ápice agudo. Escapo verde, 11-16× ca. 0,2 cm. Brácteas rosadas, 2,4-3 cm compr., com lobos eretos, 0,6-1 cm compr.; bractéolas não observadas. Pedicelo verde, 4-5 cm compr. Flores infundibuliformes, 5-5,5 cm compr.; hipanto 2-3 mm compr. Tépalas róseas, com base mais escura, oblanceoladas; as do verticilo externo 1519-nervadas; ápice mucronado, com região papilar oval; tépala superior 4-4,5 ×0,8-1 cm; tépalas laterais inferiores $4-4,2 \times$ ca. $0,8 \mathrm{~cm}$. Tépalas do verticilo interno 7-9-nervadas; ápice arredondado; tépalas laterais superiores $3,8-4,4 \times 0,8-1 \mathrm{~cm}$; tépala inferior 3,8-4,4×0,8-1 cm. Filetes rosados, em 4 comprimentos diferentes; o oposto à tépala superior 1,8-2 cm compr.; os opostos às tépalas laterais inferiores $2-2,5 \mathrm{~cm}$ compr.; o oposto à tépala inferior 2,5-2,6 cm compr.; e os opostos às tépalas laterais superiores 2,6-2,7 cm compr. Anteras amarelas, 4-5 mm compr. Paraperigônio franjado de fímbrias digitadas. Estilete rosado, ca. $2,7 \mathrm{~cm}$ compr. Estigma branco, trilobado, lobos 1-2 mm compr. Ovário ocre, obovóide 5-7 ×2$4 \mathrm{~mm}$, ca. 26 óvulos por lóculo. Fruto e sementes não observados.

Material examinado: MINAS GERAIS: Botumirim, entre Barrocão e Grão-Mogol, 13.XI.1938, F. Markgraf et al. 3520 (RB); estrada Botumirim-Barrocão, ca 3 km de Adão Colares, 30.IX.1997, A. Rapini et al. 364 (SP, SPF).

Habranthus botumirimensis pode ser diferenciada de $H$. datensis pelo ápice das tépalas do verticilo externo mucronado, lobos do estigma mais curtos, tépalas róseas, sem nervuras mais escuras (Tab. 1); ambas possuem paraperigônio franjado com fímbrias digitiformes.

É endêmica de Botumirim (MG) (Fig. 3), ocorrendo em área de cerrado e em campos rupestres.

3. Habranthus datensis Ravenna, Onira 3(16): 58. 1999.

Fig. 2 g-j; 4 a-c

Bulbo marrom, globoso, 1-4 cm diâm.; colo do bulbo 1-4,5 cm compr. Folhas verdes, lineares, 9-14-nervadas, até ca. $5 \times 0,4-0,7 \mathrm{~cm}$ durante a floração; ápice agudo. Escapo verde com base rosada, 6-16 × 0,1-0,3 cm. Brácteas esverdeadas com base rosada, 2-4 cm compr., com lobos eretos, 0,6-2 cm compr.; bractéolas filiformes observadas 


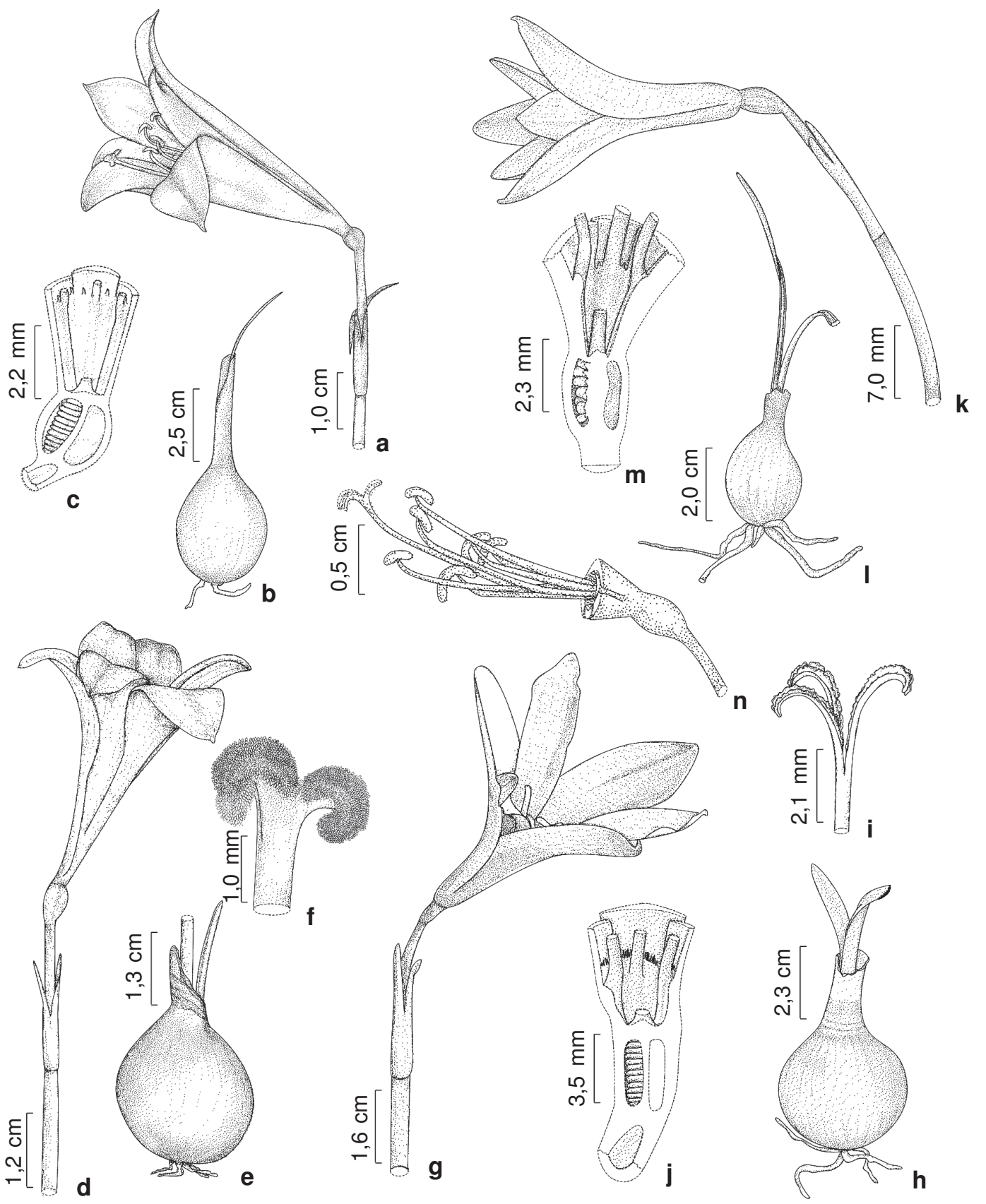

Figura 2 - a-c. Habranthus bahiensis (Arbo 5374) - a. escapo floral; b. bulbo; c. corte longitudinal na região do hipanto, mostrando paraperigônio de apêndices setiformes curvados, flanqueando a base dos filetes. d-f. H. botumirimensis (Rapini 364) -d. escapo floral; e. bulbo; f. estigma. g-j. H. datensis (Oliveira 49) - g. escapo floral; h. bulbo; i. estigma; j. corte longitudinal na região do hipanto, mostrando paraperigônio de fimbrias digitiformes. k-n.H. irwinianus (Oliveira 59) -k. escapo floral; 1. bulbo; m. corte longitudinal na região do hipanto, mostrando paraperigônio de apêndices setiformes eretos, flanqueando a base dos filetes; $n$. flor com as tépalas retiradas revelando estames em quatro comprimentos distintos e estigma em altura superior às anteras.

Figure 2 - a-c. Habranthus bahiensis (Arbo 5374) - a. floral scape; b. bulb; c. longitudinal section in hinpanthium, showing paraperigone and curved setiform appendices at the base of filaments. d-f. H. botumirimensis (Rapini 364) - d. floral scape. e. bulb; f. stigma. g-j. H. datensis (Oliveira 49) - g. floral scape; h. bulb; i. stigma; j. longitudinal section in hinpanthium, showing paraperigone of digitiform bristles. k-n. $H$. irwinianus (Oliveira 59) - k. floral scape; 1 . bulb; $\mathrm{m}$. longitudinal section in hinpanthium, showing paraperigone and erect setiform appendices at the base of filaments; $n$. flowers with tepals removed, showing stamens in four in four different lengths and stigma above the anthers. 
em alguns indivíduos. Pedicelo ocre, 2,5-4,5 cm compr. Flores infundibuliformes, $4-8 \mathrm{~cm}$ compr.; hipanto 1-4 mm compr. Tépalas brancas a rosaclaras, com nervuras mais escuras no verticilo externo, oblanceoladas; as do verticilo externo 17 19-nervadas; ápice obtuso, com região papilar concentrada no ápice, fortemente obovóides; tépala superior com base rosa-esverdeada; 3,7-6,7 ×0,8$1,8 \mathrm{~cm}$; tépalas laterais inferiores 3,9-6,7 $\times 0,6-1,6$ $\mathrm{cm}$. Tépalas do verticilo interno 9-13-nervadas; ápice arredondado; tépalas laterais superiores 3,7$6,6 \times 0,5-1 \mathrm{~cm}$; tépala inferior 3,7-6,5 ×0,6-1 cm. Filetes brancos, em 4 comprimentos diferentes; o oposto à tépala superior $0,7-1,8 \mathrm{~cm}$ compr.; os opostos às tépalas laterais inferiores $1,2-2,2 \mathrm{~cm}$ compr.; o oposto à tépala inferior 1,6-2,9 cm compr.; e os opostos às tépalas laterais superiores 2,1-3,2 cm compr. Anteras amarelas, 4-13 mm compr. Paraperigônio franjado de fímbrias digitiformes. Estilete branco, 2,5-4,1 cm compr. Estigma branco, trilobado, lobos 4-11 mm compr. Ovário ocre, largamente obovóide, 3-8 × 1-3mm, 16-36 óvulos por lóculo. Fruto obovóide comprimido, ca. $2 \mathrm{~cm}$ diâm. Sementes discóides, ca. $7 \mathrm{~mm}$ compr.

Material selecionado: BAHIA: Rio de Contas, Pico das Almas, vertente leste, $13^{\circ} 32^{\prime}$ 'S, $41^{\circ} 54^{\prime} \mathrm{W}, 28 . X .1988$, R.M. Harley et al. 25712 (CEPEC, K, SP, SPF). MINAS GERAIS: Buenópolis, estrada BR-135 para Curvelo,

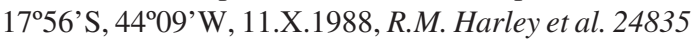
(K, SPF). Datas, BR-259, Raiz, 25.X.1999, G. Hatschbach et al. 69709 (MBM). Gouveia, córrego Cachoeira, G. Hatschbach \& R. Kummrow 49613 (MBM). Santana do Riacho, Morro do Breu, 27.IX.2002, K. Yamamoto et al. C-177 (UEC).

Habranthus datensis pode ser diferenciada de H. botumirimensis, a qual se assemelha pela presença de paraperigônio franjado com fímbrias digitiformes, pelas tépalas com ápice obtuso, com região papilar concentrada no ápice, lobos do estigma mais longos, tépalas brancas a rosadas, com as nervuras mais escuras (Tab. 1). É comum confundi-la com H. robustus Herb., que ocorre do sul do Brasil até São Paulo; no entanto, H. datensis possui tépala superior oblanceolada, com 17-19 nervuras, enquanto $H$. robustus apresenta tépala superior rômbica, com ca. 25 nervuras. Além disso, $H$. robustus apresenta estômatos somente na face abaxial da folhas, enquanto $H$. datensis apresenta estômatos nas duas faces.

Está distribuída em várias serras da Cadeia do Espinhaço e em Januária, no norte de Minas Gerais (Fig. 5), ocorrendo em áreas de cerrado. Floresce principalmente em outubro.

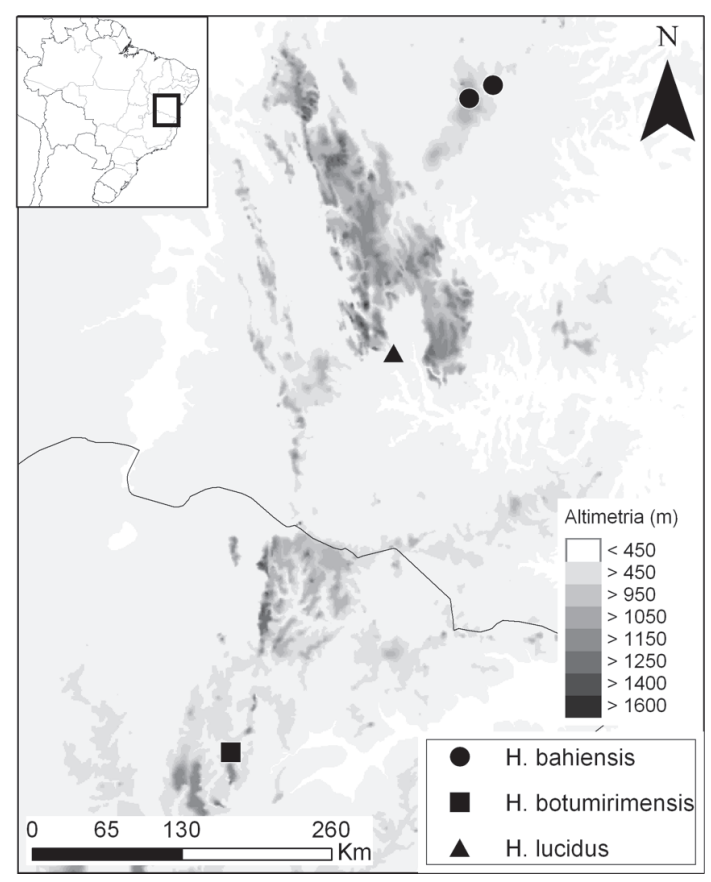

Figura 3 - Distribuição de Habranthus bahiensis, $H$. botumirimensis e H. lucidus, restritos a uma única serra na Cadeia do Espinhaço.

Figure 3 - Distribution of Habranthus bahiensis, $H$. botumirimensis and $H$. lucidus, restricted to a single mountain in the Espinhaço Range.

4. Habranthus irwinianus Ravenna, Pl. Life 26(1): 97. 1970.

Fig. 2 k-n; 4 d-f

Bulbo marrom, globoso, 1-3 cm diâm.; colo do bulbo 0,5-4 cm compr. Folhas verdes com base vinácea, filiformes, 5-7-nervadas, até ca. $3 \times 0,1-$ $0,2 \mathrm{~cm}$ durante a floração; ápice agudo. Escapo verde com ápice vináceo, 3,5-9 × 0,1-0,3 cm. Brácteas vináceas, 1,7-3,3 cm compr., com lobos eretos, 0,3-1,4 cm compr.; bractéolas filiformes observadas em alguns indivíduos. Pedicelo verdevináceo, 1-3,5 cm compr. Flores infundibuliformes, 2,6-5,1 cm compr.; hipanto 1-2 mm compr. Tépalas rosa a lilás, oblanceoladas; as do verticilo externo 11-17-nervadas; ápice agudo, com região papilar em faixa longitudinal, distribuindo-se por todo o ápice; tépala superior com mancha externamente mais escura na base; 2,3-4,4×0,4-1 cm; tépalas laterais inferiores $2,3-4,4 \times 0,4-1 \mathrm{~cm}$. Tépalas do verticilo interno 7-11-nervadas; ápice agudo; tépalas laterais superiores 2,2-4,2 $\times 0,4-1 \mathrm{~cm}$; tépala inferior 2,2-4,2 $\times 0,4-1 \mathrm{~cm}$. Filetes brancos a rosados, em 4 comprimentos diferentes; o oposto à tépala superior 0,5-1,7 cm compr.; os opostos às tépalas laterais 

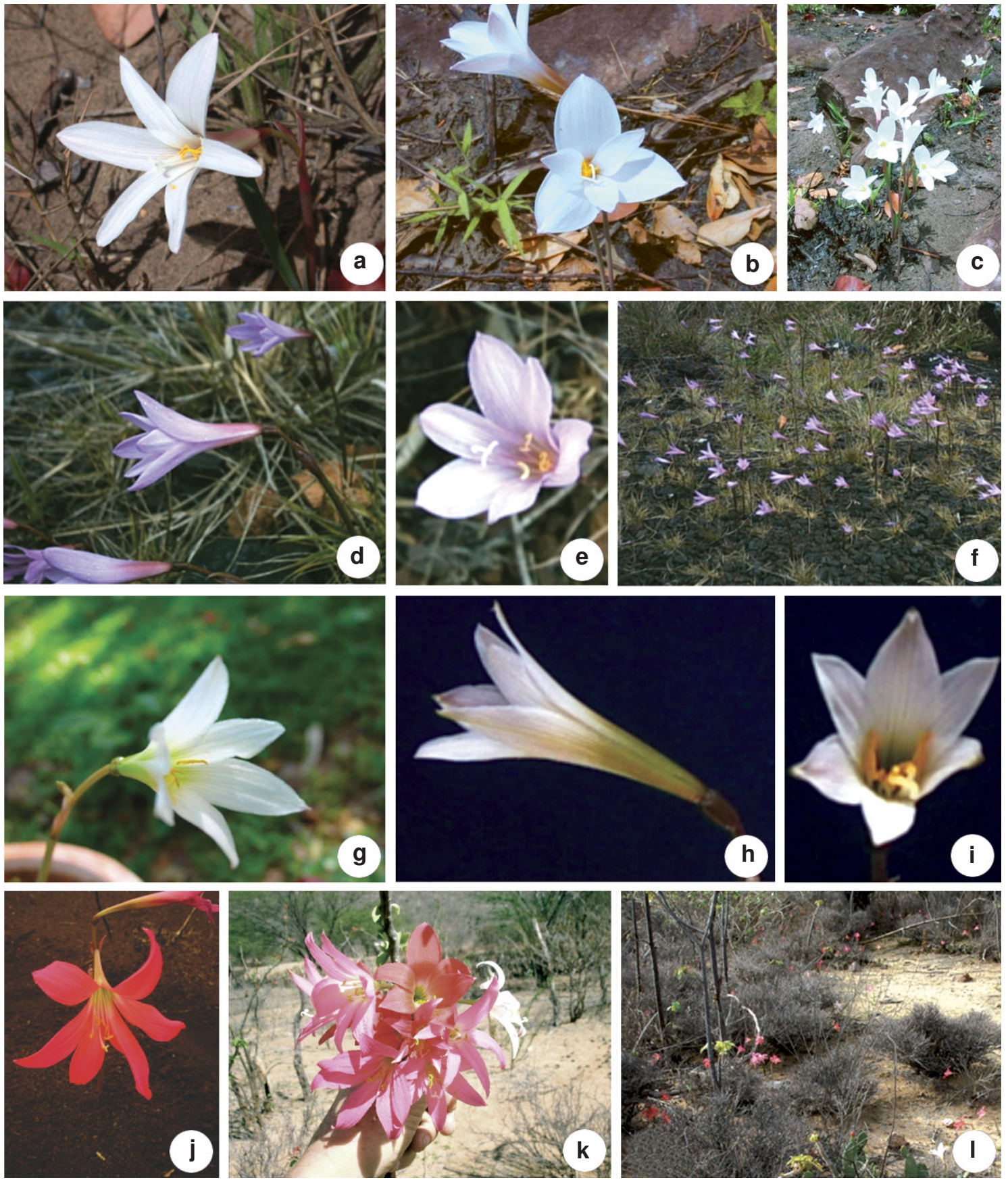

Figura 4 - a-c. Habranthus datensis - a. Serra do Cipó (MG); b-c. Serra do Cabral (MG). d-f. H. irwinianus - Serra da Piedade (MG). g-i. H. itaobinus - g. Jaíba (MG); h-i. Corinto (MG). j-1. H. sylvaticus - j. Pastos Bons (MA); k-1. Jaguarari, Flamengo (BA). Fotos J. Dutilh (a-c, g, k, l), R. S. Oliveira (d-f, h, i) e A. Gil (j).

Figure 4 - a-d. Habranthus datensis - a. Serra do Cipó (MG); b-c. Serra do Cabral (MG). e-f. H. irwinianus - Serra da Piedade (MG). g-i. H. itaobinus - g. Jaíba (MG); h-i. Corinto (MG). j-1. H. sylvaticus - j. Pastos Bons (MA); k-l. Jaguarari, Flamengo (BA). Photos J. Dutilh (a-c, g, k, l), R. S. Oliveira (d-f, h, i) and A. Gil (j). 
inferiores 0,8-2 cm compr.; o oposto à tépala inferior $1,2-2,3 \mathrm{~cm}$ compr.; e os opostos às tépalas laterais superiores 1,4-2,8 cm compr. Anteras amarelas, 2 $9 \mathrm{~mm}$ compr. Paraperigônio de apêncies setiformes eretos, pareados e flanqueando os filetes na base da porção livre. Estilete branco a rosa, 1,9-3,2 cm compr. Estigma branco, trilobado, lobos 2-5 mm compr. Ovário vináceo, fortemente obovóide, 2-4 $\times$ 1-2 mm, 20-28 óvulos por lóculo. Fruto obovóide comprimido, ca. 1,2 cm diâm. Sementes elípticas, ca. 4 mm compr.

Material selecionado: MINAS GERAIS: Brumadinho, Retiro das Pedras, 2005'35"'S, 4359'01'W, 25.IX.2001, P.L. Viana 256 (BHCB, SPF). Caeté, Serra da Piedade, 1949'25,5'S, 4340'18,7'W, 11.I.1996, V.C. Souza et al. 10116 (ESA). Catas Altas, Serra do Caraça, 20.VIII.2000, R.C. Mota 891 (BHCB, SPF). Ouro Branco, Serra do Ouro Branco, 14.VII.2002, C.C. Paula et al. 191 (VIC).

Habranthus irwinianus é facilmente reconhecida pelas flores com tépalas rosa ou lilás, paraperigônio reduzido a apêndices setiformes eretos, pareados e flanqueando os filetes na base da porção livre e pelas folhas filiformes (Tab. 1).

Está distribuída pela região sul da Cadeia do Espinhaço, nas proximidades de Belo Horizonte, com disjunções na Serra da Canastra e Ibitipoca (Fig. 5), ocorrendo em campos areno-pedregosos. Coletada com flores principalmente entre os meses de agosto e outubro, ocorrendo em campos areno-pedregosos.

\section{Habranthus itaobinus Ravenna, Onira 3(16): 56. 1999. Fig. 4 g-i; 7 a-f}

Bulbo marrom, globoso, 1,2-2,5 cm diâm.; colo do bulbo 0,5-3,3 cm compr. Folhas verdes, lineares, 8-12-nervadas, até ca. $11 \times 0,1-0,5 \mathrm{~cm}$ durante a floração; ápice agudo. Escapo verde, avermelhado na base, 9,2-30 ×0,1-0,3 cm. Brácteas rosadas, 12,8 cm compr., com lobos eretos, $0,5-1,4 \mathrm{~cm}$ compr.; bractéolas não observadas. Pedicelo verde a marrom, $1,5-4,5 \mathrm{~cm}$ compr. Flores crateriformes, $2,5-4,5 \mathrm{~cm}$ compr.; hipanto 2-8 mm compr. Tépalas brancoesverdeadas a rosadas, com ápice mais escuro e base esverdeada, oblanceoladas; as do verticilo externo 9-13-nervadas; ápice mucronado, com região papilar oboval; tépala superior 2,4-4×0,4-1,2 cm; tépalas laterais inferiores $2,2-4,2 \times 0,8-1 \mathrm{~cm}$. Tépalas do verticilo interno 7-9-nervadas; ápice agudo; tépalas laterais superiores $2,3-3,8 \times 0,3-0,9 \mathrm{~cm}$; tépala inferior $2,3-4 \times 0,3-0,8 \mathrm{~cm}$. Filetes brancos, em 2 comprimentos diferentes; os opostos às tépalas do verticilo externo $1-2 \mathrm{~cm}$ compr. e os opostos às tépalas do verticilo interno 1,4-2,4 cm compr. Anteras

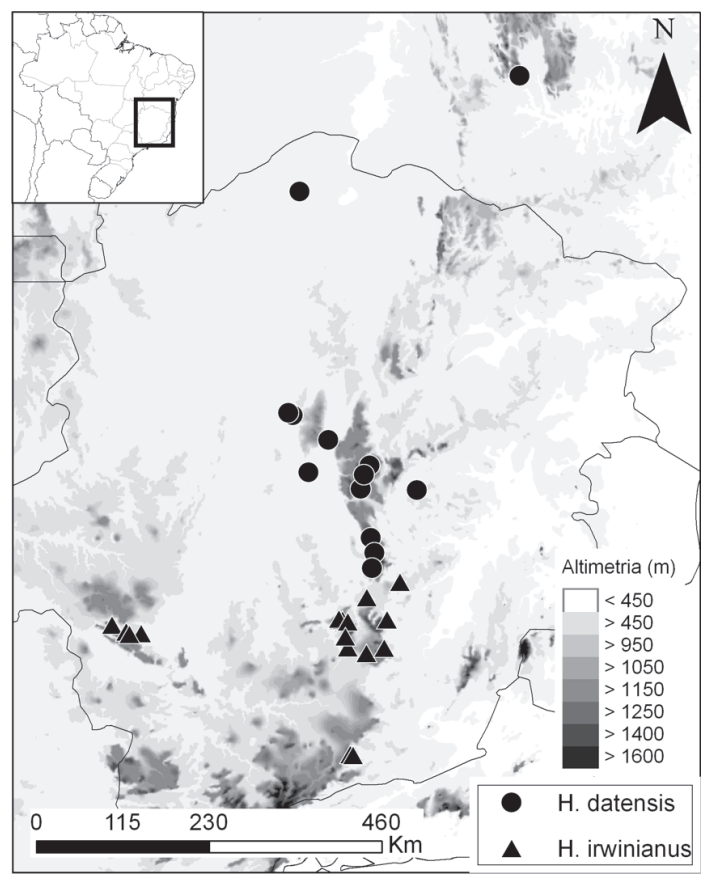

Figura 5 - Distribuição de Habranthus datensis e $H$. irwinianus, em diferentes serras da Cadeia do Espinhaço.

Figure 5 - Distribution of Habranthus datensis and H. irwinianus, in different mountains of the Espinhaço Range

amarelas, 3-10 mm compr. Paraperigônio reduzido a calosidades opostas aos filetes. Estilete branco, mais largo próximo aos lobos do estigma, 1,7-2,5 cm compr. Estigma branco, trilobado, lobos 1-2 mm compr. Ovário ocre, obovóide, 2-6× 1-4 mm, 14-20 óvulos por lóculo. Fruto obovóide comprimido, ca. 1,2 cm diâm. Sementes elípticas, ca. 5 mm compr. Material selecionado: BAHIA: Água Quente, Pico das Almas, subida norte, $13^{\circ} 30^{\prime} \mathrm{S}, 4^{\circ} 59^{\prime} \mathrm{W}, 01 . \mathrm{XII} .1988$, J.M. Fothergill 57 (CEPEC, K, SPF). Urandi, estrada para Montezuma, ca. $3 \mathrm{~km}$ da cidade, 25.IX.1997 $R$. Mello-Silva et al. 1411 (SPF). MINAS GERAIS: Buenópolis, estrada Buenópolis-Montes Claros, a 1 km de afloramento de calcário, 30.XI.2004, R.S. Oliveira et al. 67 (SPF). Grão-Mogol, córrego Escurona, 42 $57^{\circ} 48^{\prime \prime} \mathrm{W}, 16^{\circ} 35^{\prime} 42^{\prime \prime}$ S, 2.XI.1987, I. Cordeiro et al. CFCR 11321 (K, SPF). Itaobim, arredores de Itaobim, 13.IX.1984, G. Hatschbach 48134 (MBM).

Habranthus itaobinus pode ser reconhecida pelas flores branco-esverdeadas a rosadas, com ápice mais escuro, filetes em 2 comprimentos e paraperigônio reduzido a calosidades opostas aos filetes; distingue-se de $H$. lucidus por não apresentar nervuras mais escuras, flores crateriformes e ápice das tépalas externas mucronado (Tab.1). 
Possui ampla distribuição no Nordeste, Centro-Oeste (Mato Grosso e Goiás) e norte de Minas Gerais (Fig. 6), ocorrendo em caatinga, em solos mais úmidos e sombreados, e em matas de galeria, sendo comum em áreas antropizadas. Flores geralmente entre os meses de outubro e dezembro.

\section{Habranthus lucidus R.S. Oliveira, Kew Bull. 64(3):} 538. 2009.

Fig. $7 \mathrm{~g}-\mathrm{k}$

Bulbo marrom, globoso, 1,3-2 cm diâm.; colo do bulbo 1-3 cm compr. Folhas verdes, lineares, 68-nervadas, até ca. $7 \times 0,1-0,2 \mathrm{~cm}$ durante a floração; ápice agudo. Escapo verde, avermelhado na base, $9,8-16,3 \times 0,2-0,3 \mathrm{~cm}$. Brácteas rosadas, 2,2-3 cm compr., com lobos eretos, 0,7-1,3 cm compr.; bractéolas não observadas. Pedicelo verde, 2,2$3,5 \mathrm{~cm}$ compr. Flores infundibuliformes, 3,2-5,2 cm compr.; hipanto $2-5 \mathrm{~mm}$ compr. Tépalas brancas a rosa-brilhantes, com nervuras e ápice mais escuros e base esverdeada, oblanceoladas; as do verticilo externo 10-16-nervadas; ápice obtuso, com região papilar concentrada no ápice, fortemente obovóides; tépala superior 2,7-4,5 ×0,6-1,1 cm;

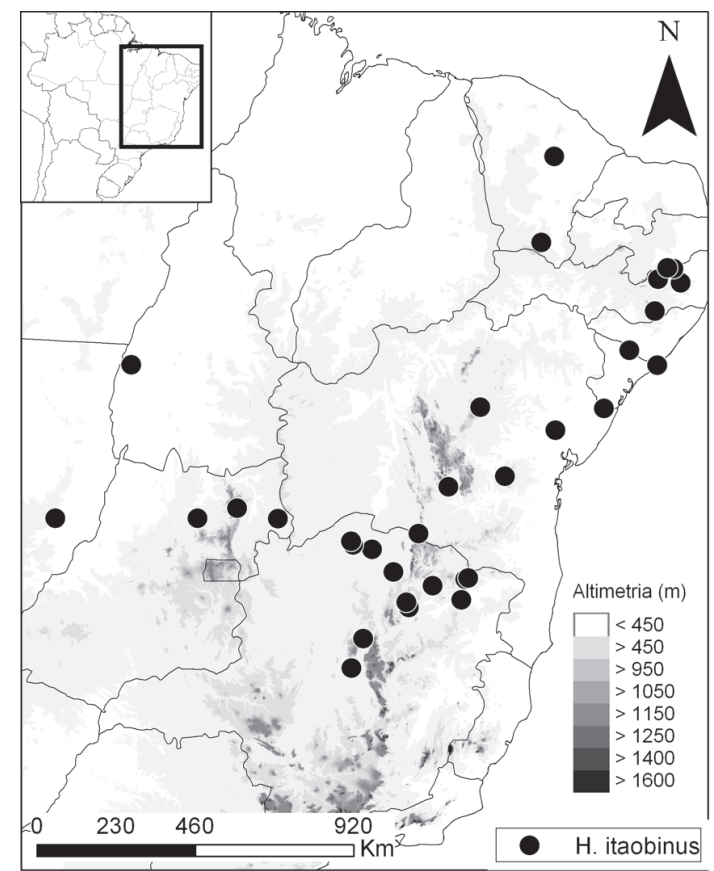

Figura 6 - Distribuição de Habranthus itaobinus, amplamente distribuído no Norte (Tocantins), Nordeste, Centro Oeste e Cadeia do Espinhaço.

Figure 6 - Distribution of Habranthus itaobinus, widely distributed in the North (Tocantins state) Northeast, CentralWest and Espinhaço Range. tépalas laterais inferiores $2,8-4,6 \times 0,5-1,1 \mathrm{~cm}$. Tépalas do verticilo interno 8-12-nervadas; ápice obtuso; tépalas laterais superiores 2,7-4,5 × 0,4$0,8 \mathrm{~cm}$; tépala inferior $2,3-4,6 \times 0,2-0,7 \mathrm{~cm}$. Filetes brancos, em 2 comprimentos diferentes; os opostos às tépalas do verticilo externo 1,2-2,2 cm compr., os opostos às tépalas do verticilo interno 1,4-2,7 cm compr. Anteras amarelas, 2-7 $\mathrm{mm}$ compr. Paraperigônio reduzido a calosidades opostas aos filetes. Estilete branco, 1,7-2,4 cm compr. Estigma branco, trilobado, lobos 1-2 mm compr. Ovário verdeavermelhado, obovóide, 3-6×2-4 mm, 12-16 óvulos por lóculo. Fruto, transversalmente elíptico, ca. 1,7 cm diâm. Sementes elípticas, ca. 4 mm compr.

Material examinado: BAHIA: Rio de Contas, estrada para o Pico das Almas, $13^{\circ} 35^{\prime}$ 'S, 41 4 $48^{\prime} \mathrm{W}, 28 . X .1988$ R.M. Harley et al. 25710 (SPF), 25711 (CEPEC, K, MBM, SP, SPF).

Habranthus lucidus pode ser diferenciada de H. itaobinus pelo perigônio rosado com estrias mais escuras, flores infundibuliformes, ápice das tépalas do verticilo externo obtuso, com região papilar concentrada no ápice, fortemente obovóide (Tab. 1).

É endêmica do Pico das Almas (Fig. 3), sendo simpátrica a Habranthus datensis e H. itaobinus. Foi coletada em beira de estrada e pasto.

7. Habranthus sylvaticus (Mart. ex Schult.) Herb., Amaryll.: 166. 1837.

Fig. 4 j-1; $71-n$

Bulbo marrom-claro, globoso, 2-3,5 cm diâm.; colo do bulbo 1-3 cm compr. Folhas verdes, lineares, ca. 13-nervadas, até ca. $12 \times 0,3-0,5 \mathrm{~cm}$; ápice agudo. Escapo verde-escuro, 13-17 × 0,2-0,4 cm. Brácteas marrom-acinzentadas, 3,2-4,5 cm compr., com lobos deflexos, 1,2-1,7 cm compr.; bractéolas não observadas. Pedicelo verde-claro, 3-4,5 cm compr. Flores crateriformes, 6,7-8,5 cm compr.; hipanto esverdeado, 10-23 mm compr. Tépalas púrpura (brancas, laranja ou rosadas podem ocorrer em algumas populações), obovais a oblanceoladas; as do verticilo externo 14 18-nervadas; ápice agudo, com apículo conspícuo, com região papilar em faixa longitudinal; tépala superior 5,78,1 ×1-1,4 cm; tépalas laterais inferiores 6-8,1×1-1,8 $\mathrm{cm}$. Tépalas do verticilo interno 10-16-nervadas; ápice acuminado; tépalas laterais superiores 5,5-8,1 ×0,8$1,4 \mathrm{~cm}$; tépala inferior $5,8-8,1 \times 0,6-1,4 \mathrm{~cm}$. Filetes vermelhos, em 4 comprimentos diferentes; o oposto à tépala superior 2,5-5,2 cm compr.; os opostos às tépalas laterais inferiores 2,7-5,8 cm compr.; o oposto à tépala inferior 3,5-6,5 cm compr.; e os opostos às tépalas laterais superiores $3,7-6,8 \mathrm{~cm}$ compr. Anteras amarelas, 3-4 mm compr. Paraperigônio formado por apêndices 

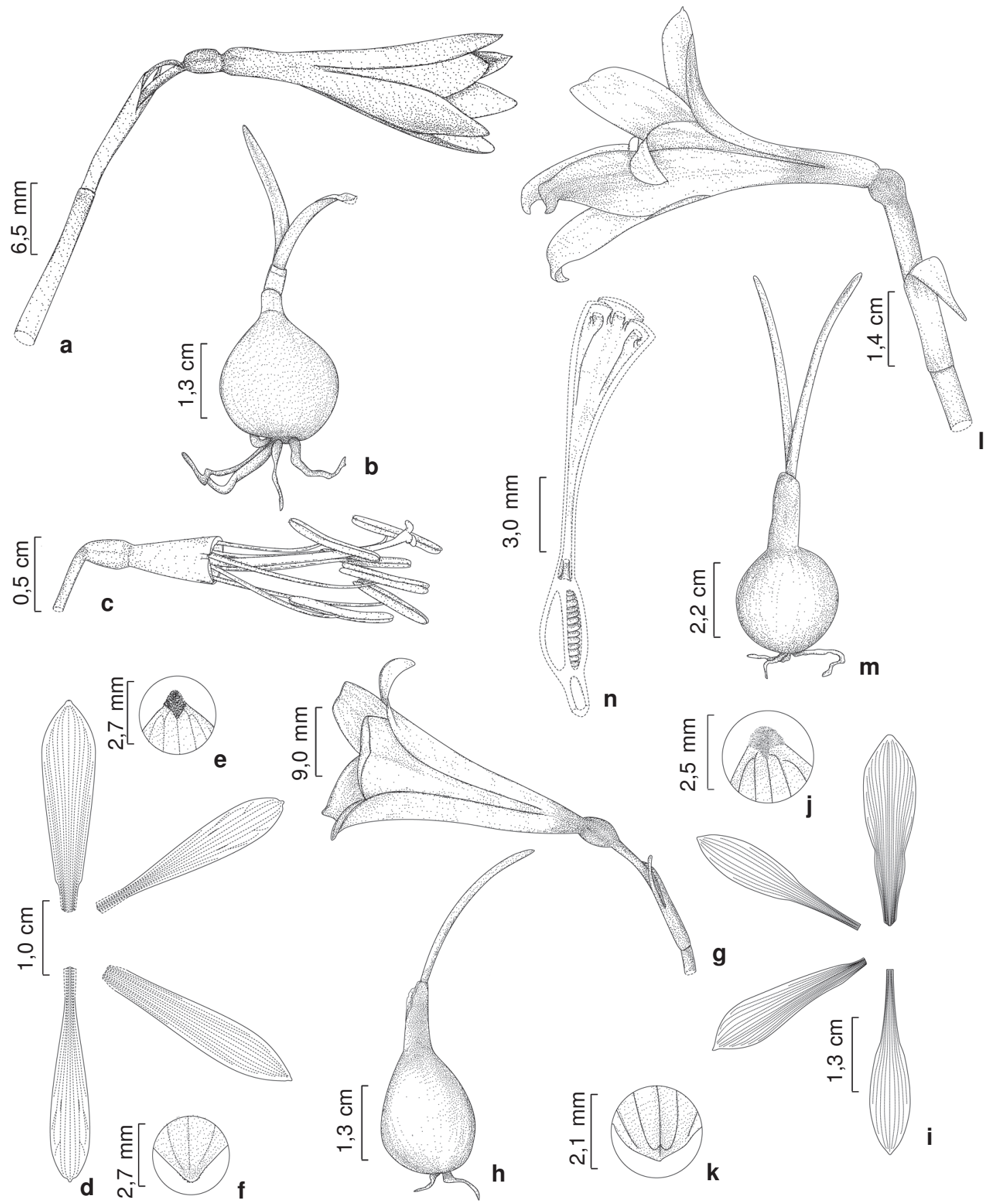

Figura 7 - a-f. Habranthus itaobinus (Oliveira 80) - a. escapo floral; b. bulbo; c. flor com as tépalas retiradas, revelando estames em dois comprimentos distintos e estigma na mesma altura das anteras; d. esquema das tépalas; e. detalhe do apículo da tépala superior; f. detalhe do apículo da tépala inferior. g-k. H. lucidus (Harley 25711) - g. escapo floral; h. bulbo; i. esquema das tépalas; j. detalhe do apículo da tépala superior; k. detalhe do apículo da tépala inferior. 1-n. H. sylvaticus (Arbo 5489) - 1. escapo floral; m. bulbo; n. corte longitudinal na região do hipanto.

Figure 7 - a-f. Habranthus itaobinus (Oliveira 80) - a. floral scape; b. bulb; c. flowers with tepals removed, showing stamens in four in two different lengths and stigma at the same height the anthers; d. tepals layout; e. detail of apicule at superior tepal; f. detail of apicule at inferior tepal. g-k. H. lucidus (Harley 25711) - g. floral scape; h. bulb; i. tepals layout; j. detail of apicule at superior tepal; k. detail of apicule at inferior tepal. 1-n. H. sylvaticus (Arbo 5489) - 1. floral scape; m. bulb; n. longitudinal section in hinpanthium. 


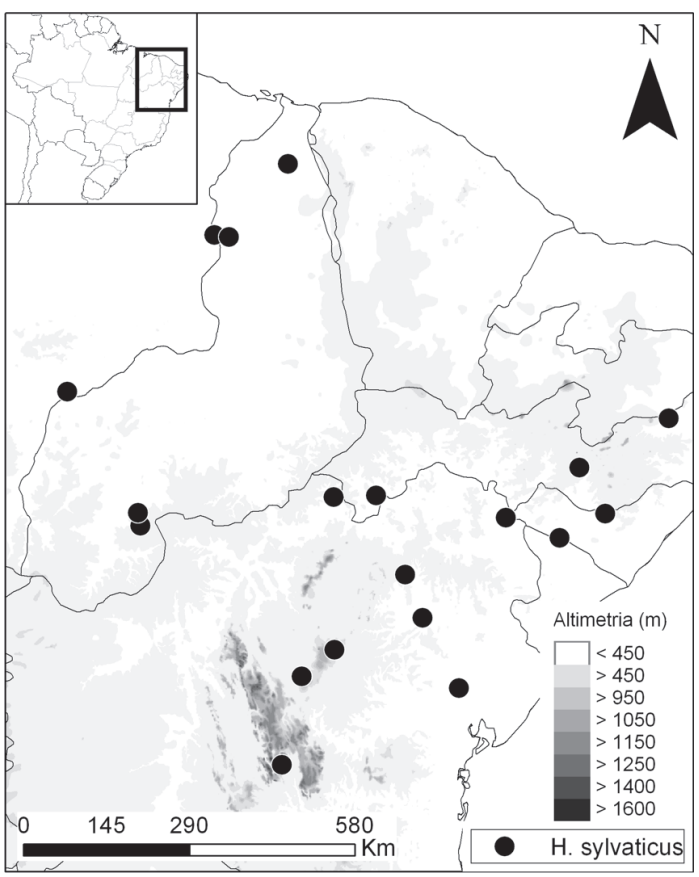

Figura 8 - Distribuição de Habranthus sylvaticus, amplamente distribuído no Nordeste e porção baiana da Cadeia do Espinhaço.

Figure 8-Distribution of Habranthus sylvaticus, widely distributed in the Northeast and Espinhaço Range of Bahia state.

em forma de ganchos, pareados e flanqueando os filetes na base da porção livre. Estilete vermelho, 4,2-6,8 cm compr. Estigma branco, trilobado, lobos 2-3 mm compr. Ovário verde-escuro, obovóide, 4$5 \times 2-3 \mathrm{~mm}, 18-24$ óvulos por lóculo. Fruto e sementes não observados.

Material selecionado: BAHIA: Abaíra, entrada de Tapera, 13¹8'S, 4151'W, 25.IX.1992, W. Ganev 1181 (HUEFS, SP, SPF). Morro do Chapéu, estrada BA-052, Irecê-Morro do Chapéu, 27.IX.1999, E. Miranda-Silva et al. 243 (HUFES, UEC). Queimadas, 1059'S, 39³8'W, 1.XI.1992, M.M. Arbo et al. 5489 (HUFES, SPF).

Habranthus sylvaticus, é uma espécie conspícua, com algumas populações formadas por indivíduos com flores de coloração diferente, variando do branco ao rosado e púrpura, até alaranjado. Assemelha-se à $H$. bahiensis, pelo paraperigônio formado por apêndices em forma de ganchos, pareados e flanqueando os filetes na base da porção livre; e pela cor púrpura das flores, que não é encontrada em outra espécie de Habranthus no Brasil. Pode ser diferenciada de $H$. bahiensis pelas flores crateriformes, geralmente maiores, hipanto mais longo $(10-23 \mathrm{~cm}$ compr.) e folhas lineares (Tab. 1).
Oliveira, R.S., Antoinette, J.H. \& Sano, P.T.

Possui distribuição ampla no Nordeste (Fig. 8), ocorrendo em caatinga. Floresce geralmente entre os meses de novembro e janeiro.

\section{Agradecimentos}

Aos curadores dos herbários consultados, o empréstimo de material; ao IBAMA e IEF de Minas Gerais, as autorizações de coleta; à CAPES, a bolsa de mestrado concedida a primeira autora.

\section{Referências}

Arroyo, S.C. \& Cuttler, D.F. 1983. Evolutionary and taxonomic aspects of the internal morphology in Amaryllidaceae from South America and Southern Africa. Kew Bulletin 39: 467-498.

Giulietti, A.M. \& Pirani, J.R. 1987. Patterns of geographic distribution of some plant species from the Espinhaço Range, Minas Gerais and Bahia, Brazil. In: Vanzolini, P.E. \& Meyer, W.R. (eds.). Proceedings of a workshop on neotropical distribution patterns. Academia Brasileira de Ciências, Rio de Janeiro. Pp. 39-69.

Gontijo, A.H.F. 1993. O relevo da Serra do Cipó, Minas Gerais, Espinhaço Meridional. Dissertação de Mestrado. Universidade de São Paulo, São Paulo. 153p.

Holmgren, P.K.; Holmgren, N.H. \& Barnett, L.C. 1990. Index Herbariorium. Part. I: The herbaria of the world. New York Garden, New York. 693p.

Joly, A.B. 1970. Conheça a vegetação brasileira. Ed. Polígono e Edusp, São Paulo. 182p.

Magalhães, G.M. 1966. Sobre os cerrados de Minas Gerais. Anais da Academia Brasileira de Ciências 38: 59-70.

Meerow, A.W. \& Snijman, D.A. 1998. Amaryllidaceae. In: Kubitzki, K. (ed.). Huber, H.; Rudall, P.J.; Stevens, P.S. \& Stüzel, T. (cols.). The families and genera of vascular plants. Vol. III. Flowering plants, Monocotyledons: Lilianae (except Orchidaceae). Springer, Berlin. Pp. 83-110.

Meerow, A.W.; Guy, C.L.; Li, Q.-B. \& Yang, S.L. 2000. Phylogeny of the American Amaryllidaceae based on nrDNA ITS sequences. Systematic Botany 25: 708-726.

Radford, A.E.; Dickison W.C.; Massey, J.R. \& Bell, C.R. 1974. Fundamentals of plant systematics. Harper \& Row, New York. 488p.

Ravenna, P.F. 1967. Contribuições ao estudo das Amaryllidaceae da América do Sul. Sellowia 19: 25-36.

Ravenna, P.F. 1970. Contributions to South American Amaryllidaceae III. Plant Life 26: 94-103.

Ravenna, P.F. 1974. Contributions to South American Amaryllidaceae VI. Plant Life 30: 29-79

Ravenna, P.F. 1978. Contributions to South American Amaryllidaceae VII. Plant Life 34: 69-91.

Ravenna, P.F. 1988. New species of South American Zephyranthes and Habranthus (Amaryllidaceae). Onira; Botanical Leaflets 1: 53-56. 
Ravenna, P.F. 1999. New species of Zephyranthes and Habranthus (Amaryllidaceae) I. Onira; Botanical Leaflets 3: 52-61.

Ravenna, P.F. 2001. New species of Zephyranthes and Habranthus (Amaryllidaceae) III. Onira; Botanical Leaflets 6: 38-43.
Stevens, P.F. (2001 onwards). Angiosperm Phylogeny Website. Version 9, June 2008 [and more or less continuously updated since]. Disponível em: <http:/ /www.mobot.org/MOBOT/research/APweb/>. Acesso em outubro 2009.

\section{Lista de Exsicatas}

Abreu, M.C. 10 (7). Acher, A. 4091 (3). Andrade, P.M. 828 (4). Arbo, M.M. 5374 (1); 5489 (7). Borba, E.L. 46 (4). Cordeiro, I. CFCR 11321 (5). Davidse, G. 11822 (5). Ferreira, A.G.81 (3). Forzza, R.C. 954; 2437 (4). Fothergill, J.M. 56-58 (5). FreireFierro, A. 1993b (7). Furlan, A. CFCR 262 (5). Ganev, W. 1181 (7). Grandi, T.S.M. 20 (4). Harley, R.M. 24835 (3); 25141; 25145; 25155 (5); 25710; 25711 (6); 25712 (3); 26699 (5). Hatschbach, G. 39682 (1); 44282, 48134 (5); 49613; 69694; 69709 (3). Hutchison, P.C. 8899 (4). Koczicki, C. 313 (4). Lombardi, J.A. 445 (4); 2070 (3); 2071 (5); 2073 (3); 4474 (5). Lopes, C.G. 247 ; 249 (7). Magalhães, M. 413 (4); 526 (4). Markgrat, F. 3520 (2). Martens, L.A. 61 (4). Matos, M.E.R. 26 (3); 27 (5). Mello-Barreto, H.L. 618; 6397; 8577; 8809; 14600 (4). Mello-Silva, R. 1411 (5); 1962 (4). Mendes, M.R.A. 143 (7). Menezes, N.L. CFSC 9416 (3). Miranda-Silva, E. 243 (7). Mota, R.C. 343, 891 (4). Nakajima, J.N. 153; 438; 501; 1279 (4). Noblick, L.R. 2925 (7). Oliveira, R.S. 47; 48 (5); 49; 58 (3); 59 (4); 66; 67; 80 (5). Pacheco, R.A. 210 (4). Paula, C. C. 191 (4). Peixoto, A.L. 1652 (5). Queiroz, L.P. 1419 (7). Rapini, A. 364 (2). Rodrigues, M.O.S. 19 (7). Romero, R. 2781; 3154 (4); 5694 (1). Salino, A. 7602 (5). Schwacke, C.A.W. 5824 (4). Semir, J. 28895 (4). Sena, M.P. 21941 (5). Silva, M.A. 3087 (5). Souza, V. C. 10116; 26958 (4). Stehmann, J.R. 1034 (4). Vasconcelos, M.F. 62 (5). Viana, P.L. 256 (4). Wanderley, M.G.L. 1242 (5). Wykrota, J.L.M. 15 (4). Yamamoto, K. C-177 (3). 